\title{
Is primitivism indigenous to Africa?
}

\author{
Cyril-Mary Pius Olatunji ${ }^{3}$ \\ Department of Philosophy, Faculty of Arts, University of Zululand \\ cyrilbukkyp@yahoo.com
}

\begin{abstract}
To know where one is coming from is to know where one is heading, and to know where one is heading is to know where one is coming from. A statement such as this is often employed successfully to help maintain an indigenous knowledge system. Western scholars, on the other hand, have effectively excluded all non-Western knowledge systems from the domain of science. In Africa, all that seems left is the maintenance of relics of history in the name of African indigenous knowledge system. Like having to decide between the undesired and the impossible, choosing between obsoletism and the 'impossible African science' seems to leave Africa with only an option of having to extol primitivism. Is Primitivism indigenous to Africa?
\end{abstract}

Especially in the Western world, culture is often associated with such things as good breeding and finesse in human relations: an educated condition; a well developed taste and capacity for the arts such as music, sculpture, literature ..., in Africa, culture often refers to the way of life of our forefathers. In this sense it is often reduced to an unchanging tradition (Okpokunu 2002, 99-126).

Keywords: Indigenous knowledge systems, indigenous knowledge, philosophy, privitivism, Africa

\section{Introduction}

Indigenous knowledge systems have come to light in recent times. The African indigenous knowledge system seems to be the African version of indigenous knowledge systems. In order to avoid ambiguities, scholars, promoters and activists of the African indigenous knowledge system (AIKS) try to demarcate between African indigenous knowledge and other bodies of knowledge, e.g. "Western science", "Asian Mystical Knowledge" or "Western knowledge". In doing so, African indigenous knowledge as a concept seems to be portrayed as an African rival or even an alternative to science. Much confusion seems to attend the demarcationist project unnoticed. The main intension of this paper is to identify one of the confusions associated with the problem of distinguishing African indigenous knowledge and to explain how it came about. This confusion has to do with the very concept of indigenous knowledge.

To begin with, the whole academic endeavour involves the history, creation and teleology of knowledge. That is, academic endeavour is all about remembering ideas, creating new ideas and projecting towards new ideas through research. Therefore, the essence of academic studies is research, because research is all about creating knowledge, confirming existing knowledge or disputing knowledge. In spite of this active involvement with issues relating to knowledge, the very concept of knowledge has perpetually remained extremely elusive.

Human beings progress to curiosity from admiration as they begin to wonder events observed in the universe. Along the line, human beings begin to ask questions: how did these things come into being? Why do they exist? What causes the orderliness or disorderliness, the nexus between events and between one event and the other? Am I sure of what I think, smell, feel, taste or hear? Do things and events have ends to which they must lead? Beyond pure curiosity, critical and analytic reflection begin about the issues that are raised. Mere curiosity turns into philosophy and philosophising. This explains why philosophy as an intellectual enterprise deals with knowledge, not necessarily by way of creating knowledge, but most importantly by way of criticising and justifying the existing knowledge (Olatunji, 2003,I-2). Philosophy is also about justifying or disproving the grounds for claims in every other discipline (Owolabi, 2000, 49). This explains why the question of knowledge is perhaps discussed more in philosophy than in other fields. The existence, nature and possibility of knowledge could be taken for granted in disciplines other than philosophy. In the history of philosophy as an intellectual field, the question of knowledge has remained an intractable one. There have been arguments on the nature of knowledge, the limit of reason, the role of experience in knowledge acquisition, the nature and criteria of truth, the nature and authority of "facts", the nature and possibility of certainty, and the degree of certainty (Miller, 1993, 140). Plato (see Popkin, R.H. and Stroll, A. 1993,189-223) has defined knowledge as nothing but a justified true belief, and consequently places knowledge on the same pedestal as any belief, faith or even intuition. By implication, Plato blurs the distinctions between the sciences, arts and even religion. Though the shortcomings of Plato's description of knowledge have been pointed out (Gettier 1963, I2I-123), scholars are yet to produce any universally accepted description of knowledge.

This paper does not necessarily intend to contest the platonic definition, to endorse it or to erect an alternative definition of knowledge. Rather, it intends to make a sceptical engagement of the conceptual scheme of the Africans in

3. Cyril-Mary Olatunji is a PhD student in philosophy at the University of Zululand and a lecturer at Adekunle Ajasin University, Nigeria.

Inkanyiso, Jnl Hum \& Soc Sci 2010, 2(1) 
relation to what they think they know about themselves and what they think they are capable of achieving rationally. That is, questioning what African scholars think about the mental capability of the Africa people, and explaining why it has come to be the way it is. Specifically, this article makes a sceptical investigation of the very conception of African indigenous knowledge.

Some non-African scholars have excluded Africans from the possibility of creating knowledge scientifically, and African scholars themselves appear to have endorsed some sorts of obsoletism and redundancy as indigenous to Africa. It becomes necessary, therefore, to ask the question "is primitivism indigenous to Africa?" This paper is only a sceptical option; it therefore does not intend to find an answer to the question. Instead, it tends to justify the rationale of the question itself. At the very end of the paper, the question still remains unanswered.

\section{Clarification of concepts}

Indigenous Knowledge: Indigenous knowledge is the model, method of acquiring and applying knowledge and the content and products of the acquired and applied knowledge, which authentically belong to a people.

Africa: Africa implies the continent and aborigines of the continent named Africa. By this definition, the White settlers in the different regions of Africa are excluded. An African scholar, therefore, is a scholar (especially those who themselves are Africans), whose theoretical focus is on the continent and people of Africa.

Science: Science refers to the theoretical and practical application of the natural sciences. Consequently, it includes physics, chemistry, biology, astronomy, geology and technology among others.

Primitivism: Primitivism signifies a theoretical position that whatever is primitive is more authentic and necessarily better. It is a belief that superiority necessarily comes with age. In practical terms, it manifests itself in having a preference for whatever is ancient, simple, savage, rudimentary or unsophisticated. Primitive here means antediluvian as opposed to modern, sophisticated or scientific.

\section{African Indigenous Knowledge}

Indigenous knowledge, either as an idea or as a system, is usually not discussed in a vacuum. It is usually discussed in connection with what is perceived to be the nature, purpose, values or consequences of indigenous knowledge. Scholars are divided over several issues surrounding the issue of indigenous knowledge, not less than they are divided on the concept and nature of knowledge itself. Wilson (1987) and Quine (1964) would make no distinction between the 'indigenous' and the 'non-indigenous' with reference to knowledge or would argue that knowledge is universal, though Quine never said that all people could attain knowledge. What he means is that whatever qualifies as knowledge must be universal in character. The implication is also that whatever is not universal in character is not knowledge. Consequently, whatever is culture bound or indigenous to a people cannot be knowledge. Hegel (1956) would want to show that there is a difference: the Western, the Chinese, the Indian and even the German knowledge systems could exist, but not the African. Stanley $(1987,117)$ on the other hand would want to demarcate between the indigenous and the non-indigenous in terms of the science and non-science divide.

It must be remembered that before the emergence of indigenous knowledge as a concept and the African indigenous knowledge as an even more recent concept (Horsthemke, 2004, 31-48), philosophers of science had attempted to demarcate between science and non-science. They tried to demarcate the goals, methods, tools and contents of science from those of other fields like metaphysics, ethics and the arts. Lakatos's popular acceptability criterion (Lakatos, 1978, I), and Popper's falsifiability criterion $(1983,256)$ are good examples. The implication of their demacationist project is that given certain criteria, certain propositions, ideas and practices are mere arts or pseudo-sciences, and consequently excluded from science. Given this demarcation between science and every other human engagement, African indigenous knowledge would either be a science or an art (pseudo-science). It is either science or excluded from science.

While it is not of any interest to take the existence of African indigenous knowledge for granted, it is equally not of interest to debate its existence or otherwise. That is, if scholars say that African indigenous knowledge is different from science, what is it? This question has to do with the nature of African indigenous knowledge itself. Laleye (2007, 164- 173) describes African indigenous knowledge as "the traditional knowledge derived from the experience of the Africans as it relates to their cultural dictates and peculiar human conditions."

Laleye argues that African indigenous knowledge, like any other indigenous knowledge system, is targeted at the immediate community from which it emanates and in which it is most relevant and appreciated. Laleye however distinguishes between African indigenous knowledge and the sciences. He argues that while the African indigenous knowledge comes from Africa, science emerges from the Western world, and both the African indigenous knowledge and the sciences are products of the environments from which they developed and emanated. 
Wallner (2005, 46-54) distinguishes between science and African indigenous knowledge systems. He writes that science is formalised and systematised with specific epistemological foundations. Nel (2005, 12-14) explores the contested aspects of indigenous knowledge discourses in contrast with Western science. In the view of Nel, Western science is the antithesis of African indigenous knowledge. He goes further and states that the validity of the difference between the two is not in question. According to Masoga (2005, iii-x) "indilinga celebrates the indigenous knowledge that has been passed from generation to generation." The implication is that indigenous knowledge is identified with something that has long existed and has been passed from generation to generation undiluted and uncontaminated.

Lemke, (1998) tries to re-evaluate the contributions of primitive African arts to modern culture. The impression that runs through Lemke's writing is either that modern culture is of external origin or that it has has been mostly influenced by external factors, while the primitive arts are indigenous. Lastly, according to Gbenga, $(2008,85-90)$

as it is argued by Horton Flakatos (1967), Ruch (1974), Oruka (1975), Wiredu (199I) and Makinde (2007) to mention a few, traditional African languages are not subjected to formal analysis, interpretation and clarification. This explains why African thoughts, beliefs, world-views and their conceptions of reality are considered pre-rational, pre-logical, anti-scientific and primitive. For some, it is on the basis of this nondevelopment of critical and analytical inclinations that the possibility of African philosophy is denied.

Here a demarcation is made, not merely between Africans and Westerners, but most of all between the mental capabilities of Africans and those of Westerners. Gbenga goes further to argue in consonance with a good number of leading African scholars he has mentioned that African languages are yet to be exposed to critical analysis.

If, therefore, African languages do not offer Africans the mental capability for rigorous conceptualisation and theoretical engagement, it does imply on the one hand that African linguists and men of letters are indicted. They are unable to rise to the challenge of producing a language with the mental categories required in the sciences. On the other hand, it means that an African cannot engage in theoretical sciences; he lacks the linguistic tools to do so.

Following the assertions of Gbenga and the other scholars mentioned above, it implies that Africans cannot have a tradition of science. By his understanding, the level of sophistication currently attained by the African languages is too low, and below the requirements of science as a theoretical formulation and practical application of mental categories and models. However, the implications of the sharp demarcation between the nature, concept and content of science and African Indigenous knowledge systems is that if one is modern, sophisticated, knowledge par excellence and scientific, the other must necessarily be obsolete, primitive, pseudo-science or mere arts. Put differently, if science is Western, sophisticated and modern, then African indigenous knowledge must be primitive, mere arts or just something different. In addition, if the culture and language of the West is capable of promoting science, African culture should only be capable of promoting something different, like arts, or something lesser like pseudo-science.

If personal experiences are to count as anything tangible in such an academic paper as this, it may be necessary to narrate a few. Sometime in the 1980s, I tried to attend a church service in a new growing church. I was turned back from the entrance for putting on a Yoruba traditional dress. The usher told me that traditional attire and everything traditional were associated with ancestors, demons and Satan. I was told that unless I was in coat, shirt and trousers I could not be allowed to worship with them. A few years later, there was a land dispute between my town (Isua Akoko) and a neighbouring village. The youths from my district were summoned to the market square and directed to go and carry out some militant operation on the disputed land. After the public address, the elders told us to meet them at the site, located several kilometres away along some rocky and narrow footpaths. To my dismay, we met the elders at the site. Being inquisitive, I tried to inquire how those elders, some of whom were in their 80 s and 90 s, had got to the site before the young boys, but I was hushed. These stories confirm that Western culture is more acceptable even within the Christian religious setting, while the African alternative (as distinguished by scholars) lacks explanations, except probably in secret. It also shows that the attitude of distinguishing between the African and the Western, of seeing the Western as acceptable, and of condemning African idea and materials to secrecy as found among scholars, has influenced even the common people.

During the anti-colonial struggle, for independence in Africa, many of the African nationalists and political elite and leaders had thought that the only way by which Africa could be truly independent was to contrast the African system with the colonial system as far as possible. The anti-colonialist outlook explains the anti-liberalist political fashions of the earliest African leaders, Nkrumah (1964), Kenyatta (1965) and Biko (2000, 360-363). In the same vein, scholars, especially in philosophy, tend to differentiate irreconcilably between African philosophy and what they call Western philosophy. The works of Sodipo (1973, I2-20), Hountondji, P. (1983), Wiredu (2000, I86-204), Oruka (2000, 99-108), and Senghor (1963, 9-22) are good examples.

Inkanyiso, Jnl Hum \& Soc Sci 2010, 2(I) 
In another dimension, because African scholars never traced the political problems of the continent further than colonialism, they seem logically justified to tend to oppose anything identifiable with the colonialists. Perhaps, they felt that the rest of the world would see Africa as inferior if the African worldview were found to tally with any other, let alone, the colonial intruders'. Consequently, they try to distance the African views from whatever appears Western and if possible oppose it as much as possible. This explains the call for a return to the "past" which runs through the philosophical discourse of many of the African nationalist scholars like Nkrumah, Senghor and Menkiti. It results in a kind of primitivism: a belief that the former is better and more reliable. This intellectual approach is by no means limited to the earliest nationalist scholars. Even modern Africans still think almost the same way, as has been seen in the cases of Du Toit, Nel, Laleye and others.

Aside from the anti-colonial struggle, the sharp contradistinction between African indigenous knowledge and science could also be traced to the philosophical tradition in which many African scholars have been trained. Makinde (1998: I-2) argues that the idea of the immortality of soul developed by Pythagoras has led to the distinction between the mind and the body, and between reason and the senses in modern epistemological debate between the rationalists and the empiricists. In Makinde's opinion, it is this ontological dualism that has nurtured modern intellectual culture. The modern intellectual culture is therefore one of demarcating and making sharp distinctions between objects, positions, views, schools of thought and disciplines; it is one in which identification of differences is considered an academic virtue and excellence.

Both the anti-colonial struggle origin and the partitionist intellectual foundation of modern African scholars are only half the truth. The imperial nature of colonialism cannot be ignored. The imperial system of the colonialists would certainly have attempted to suppress the African cultures by illegitimating them and rendering them as inferior, primitive, obsolete, underdeveloped, uncivilised and eventually as clandestine cultures. There is no point arguing whether colonialism has actually suppressed the African cultures or not. The current position of the numerous European languages in Africa is sufficient evidence for a logical conclusion. Therefore, African scholars, especially those who are victims of the trio of anti-colonial struggle, intellectual partitionism and colonial imperialism would naturally tend to demarcate sharply and irreconcilably between African indigenous knowledge and science (sometimes portrayed as alien and inimical to Africans). The situation is also expected to produce a sort of mental dualism and mental alternation between the opposing schemas: the primitive and the modern, art and science, the indigenous and the standard, or the Western and the African.

\section{Historical dialectics, Western Futurism and Epistemological Exclusionism versus African knowledge system}

Perhaps, the most appropriate place to begin a discussion on the futurism of the Western knowledge system to which the name science has been abrogated is Hegelian dialectics. G.W.F. Hegel is sometimes regarded as the peak of German idealism. What distinguishes Hegel's idealism from those of Fichte and Schelling is the dialectical schema of his philosophical system. The Hegelian system comprises the dynamics of the unfolding totality of an active reality (see Popkin and Stroll: 1993, 83-85, 133-134). A number of triads could be found in the Hegelian system. For instance, the Hegelian reality is made up of (I) the spirit (mind), which is the idea for itself; (2) nature, which is idea outside of itself, and (3) logic, which is the idea in itself. Each of the three is subdivided into three and each of the subdivisions is further divided into three. Hegel's triads culminate in a dialectical method.

The dialectical method of Hegel looks like an attempt at reconciling the problem of the 'one' and the 'many,' which had started from the Ancient Greek thinkers (Hegel 1975). In spite of the resemblance that the Hegelian method bears with the earlier thinkers, his philosophy builds a foundation upon which much of the social and intellectual systems of generations after Hegel came to be shaped. Hegel believes that reality is spiritual, and that spiritual reality is continually changing and advancing to the ultimate state, which he calls the Absolute Spirit. In the context, there is a sort of give-andtake synthesis between opposites consisting of the thesis and the antithesis. In the give-end-take unity of opposites, a new state is produced called the synthesis (Hegel, 1956). Hegel believes that this process is constantly and continuously ongoing in all spheres of existence and in the totality of existence. In Hegel's opinion, this constant conflict is teleological in nature; it pictures reality as constantly evolving towards the best. The implication of this is that the in the dialectical context, the emerging synthesis is seen as superior to previous states.

Perhaps the most astounding application of Hegel's dialectics could be found in Marx's dialectical materialism. The Marxist dialectical materialism, only a materialistic adaptation of Hegel's historical dialectics, is the view that reality is matter and motion, which constantly evolves historically in accordance with the principles of constantly synthesising the opposing social and political states towards a perfect communist state. Every succeeding state is therefore an improvement over the preceding state. The influence of a combination of Hegelian dialectics and the contextualised 
version of it by Karl Marx (Popkin and Stroll: 1993, 82-94) on social situations of the $21^{\text {st }}$ century cannot be over emphasised. The underlying teleology of Hegelianism adapted by Marx seems to have conditioned and engineered scholarship and society in general towards a sort of belief that new ideas are better than the former. Motivations towards new inventions and discoveries in science, technology and arts are perhaps under the influence of looking forward to something better than the previous. The influence is more pronounced in the Western world. This could be identified as a sort of futurism; a belief that the present is an improvement on the previous and that the future or the yet to be discovered would be better than the present. There is therefore an unrestrained craving for new inventions without considering the impact of the new inventions on the existential condition of the people the new discoveries are meant to serve. Though Karl Marx is identified with socialism and communism, which the liberalists and the capitalists have identified as conservative, capitalism seems to owe its underlying creativity to the dialectic materialism of Karl Marx more than to the alleged competitive feature of the capitalist system.

Epistemology is often regarded as an aspect of philosophy relating to how to know, what to know and the criteria for knowing and accessing knowledge. It is usually held that there are two opposing schools of thought in epistemology: rationalism and empiricism, the latter sometimes called positivism (Hamlyin, 1970). However, the alleged opposing schools are together opposed to the sceptical school (Popkin, 1979, 244). Since philosophy itself is generic, it becomes possible to have the epistemology of other disciplines such as medicine, communication, language, religion, politics, biology and even agriculture. The controversies that are found in most other fields ensue from the epistemological positions of the scholars involved. Consequently, most controversies among scholars are applied epistemological issues (Olatunji, 2007, I). The unnecessary demarcations between the perceiving subject and the object of perception in rationalism and empiricism and to some extent in scepticism have been vehemently criticised by the phenomenologists. Though the phenomenologist's solution to the demarcation has been argued to be fallacious, our immediate interest is not to join issues on that controversy. The controversy has helped at least to accept the possibility of exclusionism in Western epistemologies.

Consequent to epistemological exclusionism, there have been concerted efforts to differentiate between science and non-science. Normally, it is believed that the scientific statement is true, correct and knowledge par excellence (Aigbodioh, 1997, 57). Scholars think it is in the best interest of scholarship to make a clear demarcation between science and non-sciences. To this end, a number of criteria have been offered. It is not unusual to think that what distinguishes the scientific from the non-scientific is the procedures of observation, experimentation and generalisation. However, scholars have argued that abrogating such procedures to engagements in the fields of science alone are arbitrary and therefore a weak argument. These scholars consequently try to offer alternative explanations and criteria for demarcating between the scientific and the non-scientific. Using the list provided by Aigbodioh $(1997,57)$, the first is the popular acceptability criterion offered by Lakatos (see Oludare 2004, 48-58). Lakatos argues that a statement is scientific if many people agree seriously that it is true. Unfortunately, there are numerous beliefs and ideas which many people hold to be true but which are never considered to be scientific. For instance, the number of people who believe in the existence of God or ghosts has not raised the belief in God to the level of the sciences. Lakatos also offers the 'research programme' criterion. This criterion could be roughly stated as meaning that a statement is scientific if it is progressively applicable. For instance, on the basis of progressive applicability or instrumentalism, such concepts as the ether and the gene have been generally accepted to exist on the basis of their effects and uses rather than on the basis of any objective support.

Unfortunately, instrumentalism cannot be a reliable criterion for demarcating between the scientific and the nonscientific because it could be applied politically to exclude some and include others, as long as it works. This is a version of instrumentalism. The objective support criterion usually referred to as the verifiability criterion is also an alternative criterion. This criterion is on the basis that scientific research directly reports observations. Experience has shown however to the contrary that all statements and observations are theory-laden and value-laden. What the scientist describes are not things as they are out there, but how he or she thinks they are. What we call the scientific are no more than subjective explanations taken too seriously. Karl Popper also offers the falsifiability or refutability criterion. This implies that to be scientific is to be testable or verifiable. Many scholars have rejected this criterion on several bases (Aigbodioh, 1997, 63). For instance, Newton's, Kepler's and Galileo's theories are considered scientific because their alleged truths could be tested and verified (see Aigbodioh, 1997, 62-64). Unfortunately, Popper (1979, 16) himself observes that Newton's theory is found to contradict both Kepler's and Galileo's theories on the same issue. It should have been expected that if one is scientific, the other should be non-scientific, and if one is true, the other should be false. To date the two are still held to be scientific.

Kuhn (1970, I-18 and 187-206) has also argued to the effect that the demarcation between science and other knowledge systems is very arbitrary because the mode by which adherents of one paradigm remain loyal to their paradigm even when it has been disproved, or change to another even when nothing so seriously defective has been Inkanyiso, Jnl Hum \& Soc Sci 2010, 2(I) 
associated to the previous is not different from the manner in which people change parties or remain loyal to their parties in the political sphere. Kuhn's argument is that if science is no more than the politics of epistemic community then the demarcation between science and non-science is arbitrary.

In spite of the criticisms of Thomas Kuhn and a number of other scholars, many are still very committed to demarcating between the process, the content and even the ends of science and those of non-sciences; say culture, arts, social sciences. According to Sogolo (1993, I I5); "it has to be granted that the language of discourse in traditional African culture in the matter of health and illness is different from that of orthodox medicine." Sometimes, the demarcation is done in a way that seems to portray that the two are irreconcilable, and that the validity of one implies the invalidity of the other as a science. Usually, the non-sciences are classified under various names and titles such as arts, crafts, traditional skills. In addition to demarcating between science and non-science, therefore, the exclusionist epistemology which forms the basis for the demarcation criteria also excludes African indigenous knowledge from the scheme of rational, systematic and scientific discourse. The demarcation often made between science and arts may not really be as obvious as scholars tend to portray. Science in a loose sense is believed to include engineering and technology, for instance. There would probably not be an invention of a car or mobile communication system gadgets without the art of design and shapes. Technology therefore is no more than modern art. This artistic aspect of modern science is often forgotten when making a boundary between art and science, and consequently between Western and the African.

Gough (2002, 1217-1237) accuses Western scholars of exclusionism, because they have labelled and classified other knowledge systems as non-formal, uninformed, and non-contemporary, and, consequently non-scientific. Du Toit (2005, 55-73) also notes that Westerners often see indigenous knowledge as the African equivalent of Western science, technology and rationality, with nothing but mere symbolic value to mark the new wave of renaissance in Africa. Unfortunately, African scholars are themselves not less exclusionists that their Western counterparts. They are equally quick at distinguishing between African indigenous knowledge and Western scientific knowledge. By implication, they have attributed the current and modern apex of knowledge to science and have conceded science to the West.

For instance, Mkabela (2006, v-viii) notes an ongoing debate which demands a methodological choice between conventional scientific methods and indigenous knowledge (centred) approaches when dealing with Indigenous knowledge System (IKS). According to Castiano, (2005, v-vii) "most indigenous knowledge has been perceived in the near past, even among some intellectuals, as marginal and only suitable for traditional societies." Magoro \& Masoga (2005, 4I4-428) conceptualise indigenous knowledge as a system concerned with many aspects that are important to local people and disseminated from generation to generation. Perhaps one of the clearest formulations of the African scholars' misconception of indigenous knowledge is Kolawole (200I, 13-15) and Kolawole (2005, 1427-1443) who argue that indigenous knowledge equals local or traditional knowledge peculiar to a particular culture or to a people in a particular locality.

While Western scholars tend to be future-centric and sometimes excessive in their progressive impulse, African scholars tend to be pro-primitive. They seem to defend primitivism in the name of the indigenous. Should African indigenous knowledge mean returning the past, or bringing back the past methods in their uncontaminated forms? Should other indigenous knowledge related concepts such as African renaissance and ubuntu be interpreted in the retro-centric manner?

Arguably, rather than merely reproducing the past in their original forms, should scholars of African indigenous knowledge not think of how, for instance, the concept of ubuntu could be employed to surmount some existential problems facing contemporary human society?

In a simple term, ubuntu as an aspect of African renaissance should hardly be anything like a return to the way things were done in the past. First, the past may not be suitable for the present. Time and tide have disposed of the past. In fact, even if there had been no colonial intervention or cultural imperialism, Africans on their own could still have abandoned the primitive cultures by now. Second, it may be impossible to return to the past. Even if it is possible to return to the past or to recall the ancient socio-cultural models, the alleged past is controversial. When in the past should be the appropriate spot to begin from or to return? Some of the historical ideas were socio-cultural devices of their times to deal with social problems based on the available level of knowledge. They were as scientific as they could be in their time. Applying them outside of the context that necessitated their existence is no more than holding on to the old manual typewriter in spite of better and advanced technologies. It would mean holding on to the relics of history rather than to their lessons and values. Rather than returning to the past or recalling the past as in some retrospectivist approach to renaissance, a reconstruction of the past might be more appropriate by keeping the underlying values.

What exactly does reconstructing the past mean? The influence of the past on the present is hardly ever in doubt, as is the influence of the present on the future. Pasts of the said influence are good and others are not. Reconstructing the past therefore would mean tracing the root of the bad influences and constructing the present in such a way that eliminates 
the unwanted bad influences of the past or neutralises the effects of the said past. Consequently, if it is possible to return to the past, the first thing should be to clear the controversies and erect a good historically and intellectually reliable structure about the African past. The reconstructed past could consequently serve as the point of renaissance. Renaissance on the other hand should not one that ensures that Africa remains perpetually in the past while others look to the future.

The demarcationist approach that polarises Africa and the West regarding science and indigenous knowledge could be a mistaken opinion. The reason is that, though the invention of airplanes, gunpowder, warships or even of some mathematical methods may have come from Europe, America, Asia or Egypt, the scientific scheme itself is universal. It is not different from saying art is indigenously African or technology is indigenously Asian. The particular invention is only an application or practical manifestation of the scientific scheme. Science does not become European simply because Europe invents or discovers a thousand things while America discovers or develops only ten or none. There is also no scientific innovation or invention that was ever made universally. Most inventions were made by a single or a few individuals as indigenous knowledge, and consequently put into the positive use by people from every parts of the globe. It is neither unscientific nor opposed to science at any point.

The material contents or the relics of the primitive ideas, whether African or European, were devices to serve human needs within the historical contexts that produced them. They could only be relevant in modern times as histories and as take-off points. They are not relics for veneration and peaks of achievements. Perhaps, too, no new invention would ever have been made if scientists were to go about glorifying their previous achievements. It is conceivable that innovations would have been rare if scholars made sure that the original styles, methods and models of past achievements, discoveries and inventions are retained and unmodified either in the name of renaissance or indigenous knowledge in the manner some African scholars tend to advocate for Africa's past.

\section{Conclusion}

After a brief outline of samples of definitions of African indigenous knowledge, this paper resumes with samples of African scholars' understanding of African indigenous knowledge. It is discovered that many African scholars look to the past in order to understand the system of knowledge indigenous to Africa. An analysis of Western scholars reflects some sort of exaggerated futurism. In addition, some African scholars are of the opinion that to have an authentically African indigenous knowledge, the scope of the alleged indigenous knowledge must be distinguished from the realm of alleged Western sciences. In like manner, Western scholars have successfully excluded African indigenous knowledge and any other alternative for that matter from the corpus of scientific knowledge. Given this scenario, African indigenous knowledge is seemingly banished to the clandestine realm of the obsolete and the mediocre.

There is a saying in Yoruba language that t'omode ba subu a maa wo iwaju, t'agba ba subu a maa wo 'bi 'to ti f'ese ko. It literally means "when a child falls (has challenges), the child looks to the front, but when the elder falls (has challenges), he looks back to see the cause of his fall." In like manner of the Yoruba, many Africans see it as a social virtue or wisdom to look to the past for solutions to present situations; and childish or premature to look to the future for solutions for past, present and future challenges. It has not been of serious importance in this paper to judge the adequacy of the weltanschauung of looking backward for solution; it is obvious that one who does not know where he or she is coming from may not know where he or she is heading. It has also not been of any serious relevance to judge the adequacy of excessive futurism. It however confirms how and why the intellectual tradition in Africa seems to extol primitivism.

There is a need to replace the theoretical background of demarcationism and exclusionism. That is, the objectsubject, and the 'we versus them' outlook of demarcationist epistemology associated with rationalism and empiricism need to be replaced with a spontaneous and integrative holism. Constructing such a theoretical ideal could perhaps require a separate work other than this. It is therefore committed to future research. However, the question "is primitivism indigenous to Africa?" is a valid one. If the question is valid, but the answer to the question is "no," then, it could be further asked: should primitivism not be replaced by a more viable alternative? If primitivism needs a replacement, is science Western? Can science not be African? Is it the concept of science that is Western or the method and content of its engagement? Is Western unbridled futurism and exclusionism a better alternative? Until these questions find answers, African indigenous knowledge may continue to promote primitivism or be lost for lack of identity.

\section{References}

Aigbodioh, J. A. (1997). Philosophy of Science: Issues and Problems. Ibadan: Hope Publications.

Biko, S. (2000). The Definition of Black Consciousness. P. H. Coetzee and A. P. J. Roux (eds.), Philosophy from Africa. (pp. 360363). Oxford: Oxford University Press

Castiano, J. P. (2005). Foreword: can indigenous knowledge provide solutions to Current Problems? Indilinga - African Journal of Indigenous Knowledge Systems, 4 (2), v-vii.

Inkanyiso, Jnl Hum \& Soc Sci 2010, 2(I) 
Du Toit, C. W. (2005). The Environmental integrity of African Indigenous knowledge systems: probing the root of African rationality. Indilinga - African Journal of Indigenous Knowledge Systems. Vol 4 ( I), 55-93.

Gbenga, F. (2008). African Philosophy and the method of ordinary language Philosophy, African Journal of Political Science and International Relations, 2 (4), 85-90.

Gettier, E. (1963). Is Justified True Belief Knowledge? Analysis, (3), I 2 I - I 23.

Gough, N. (2002). Thinking/acting locally/globally: Western Science and Environmental education in a global knowledge economy. International Journal of Science Education, 24(I I), I2 I 7-I 237.

Hamlyn, D. W. (1979). The Theory of Knowledge. London: The Macmillan Press.

Hegel G. W. F. (1956). The Philosophy of History. Ontario: General Publishing Co.

Horsthemke, K. (2004). 'Indigenous Knowledge' - Conceptions and Misconceptions. Journal of Education, $32,31-48$.

Kenyatta, J. (1965). Facing Mont Kenya, New York: Vintage Press.

Kuhn, T. S. (1970). The structure of scientific revolution. Chicago: The University of Chicago press.

Lakatos, I. (1978). The Methodology of Scientific Research Programme. Philosophical Papers. I, I.

Laleye, S.A. (2007). Africa's Indigenous Knowledge: science and the quagmire of sustainable development, Journal of Applied Philosophy, I(I).

Lemke, S. (1998). Primitivist Modernism: black culture and the origins of transatlantic modernism. New York: Oxford UP.

Kolawole, O.D. (200I). Local knowledge utilisation and sustainable natural development in the 2 Ist century. Indigenous Knowledge and Development Monitor, 9(3), I3- 15.

Kolawole O.D. (2005). Mainstreaming local people's knowledge and implications for higher education in the South. South African Journal of Higher Education, 19(200). 1427- I443.

Magoro, M.D. and Masoga, M. (2005). Aspects of indigenous knowledge and protection in small-scale farming systems: a challenge for advancement. Indilinga - African Journal of Indigenous Knowledge Systems. Vol. 4 (2), 4I4-428.

Makinde, M.A. (1998). African Philosophy, Culture and Traditional Medicine. Ohio: Centre for International Studies.

Marx, K. (1980). Capital. New York: International publishers.

Miller, E.D.L. (1993). Questions That Matter. New York: McGraw-Hill, Inc.

Mkabela, Q.N. (2006), Foreword: towards a holistic (Indilinga) approach to indigenous knowledge systems scholarship. Indilinga - African Journal of Indigenous Knowledge Systems, Vol 5 (I), V-Viii.

Nkrumah, K. (1964). Conscientism: Philosophy and ideology of decolonization and development with particular reference to the African revolution. London: Heinemann.

Okpokunu, E. (2002). Major culture areas of Nigeria. A, D. Nzemeke and E. O. Erhagbe (eds.). Nigerian peoples and culture $\left(2^{\text {nd }}\right.$ ed.). Benin City: Mindex Publishing Co.

Olatunji, C.P. (2007). Ethical Issues are epistemological issues moralized. The ethical spectacles: http://www.spectacles.org/0807/ olatunji.hotmail.

Olatunji, C.P. (2003). A Critical Study of the Representative Realist Theory of Perception. Unpublished dissertation submitted to the Department of Philosophy, Adekunle Ajasin University Akungba.

Oruka, H. O. (2000). Sage Philosophy. P.H. Coetzee and A.P.J. Roux (eds.) Philosophy from Africa. (pp.99-108). Oxford: Oxford University Press.

Owolabi, K.A. (2000). The nature and problems of epistemology. Ibadan: Grovacs, $49 \mathrm{ff}$.

Popkin, R.A. and Stroll, A. (1993). 83-85, I33-I 34 Philosophy made simple, New York: Doubleday

Popkin, R.H. ( 1 979). The History of Scepticism: From Erasmus to Spinoza. California: University of California Press.

Popkin, R H. \&Stroll, A. (1993). Philosophy Made Simple. New York: Double Day.

Popper, K.R. (1979). Objective Knowledge. Oxford: Clarendon Press.

Popper, K.R. (1963). Conjecture and Refutations. London: Routledge and Kegan Paul.

Quine, V.W.O. (1964). From a Logical Point of View. Cambridge: Harward University Press.

Sodipo, J.O. (1973, 12-20. Notes on the Concept of Cause and Chance in Yoruba Traditional Thought. Second Order, (2), 2

Sogolo, G. (1993). Foundations of African Philosophy, Ibadan: Ibadan University Press.

Stanley, D. (1987). In Search of the Primitive: A critique of civilization. New Brunswick: Transaction Books.

Wallner, F. (2005). Indigenous knowledge and Western science: contradiction or cooperation. Indilinga - African Journal of Indigenous Knowledge Systems, 4(i), 46-54.

Wilson, D. (1987). Traditional Media in Modern African Development. Module on Development Communication, (2). In J.K. Ayantayo. (20I0). The Ethical Dimension of African Indigenous Communication Systems: an Analysis. Lumina 2 I (I), I-I5.

Wiredu, K. (2000). On decolonising African religion. P.H. Coetzee and A.P.J. Roux (eds.), Philosophy from Africa. (pp. I86-204). Oxford: Oxford University Press. 